www.jmscr.igmpublication.org

Impact Factor (SJIF): 6.379

Index Copernicus Value: 71.58

ISSN (e)-2347-176x ISSN (p) 2455-0450

crossref DOI: _https://dx.doi.org/10.18535/jmscr/v6i4.141

Journal Of Medical Science And Clinical Research

\title{
Comparative Study of High Sensitivity C-Reactive Protein with Body Mass Index in a Population of Alappuzha, Kerala
}

\author{
Authors \\ Dr Sunayana Mathew ${ }^{1}$, Dr Rose Davy.C ${ }^{2}$, Dr Deepa Rajendran ${ }^{3}$ \\ ${ }^{1}$ Moolayil H, Ruby Nagar Post, Changanacherry, Kerala \\ ${ }^{2}$ Additional Professor, Department of Physiology, Government T.D. Medical College, Alappuzha, Kerala \\ ${ }^{3}$ Assistant Professor, Department of Physiology, Government T.D. Medical College, Alappuzha, Kerala \\ Corresponding Author \\ Dr Sunayana Mathew \\ Email: sunmath07@gmail.com,Ph:+919633399732
}

\begin{abstract}
Background: High-sensitivity $C$-reactive protein (hs-CRP) is known as a marker for low-grade inflammation and atherosclerosis. Due to its cardiovascular risk owing to atherosclerosis, its possible correlation with obesity in a local population was assessed, using BMI as the parameter.

Objective: To study correlation of hs-CRP with BMI in a population of 25-45 years in Alappuzha, Kerala.

Materials \& Methods/Procedure: 111 subjects of either sex, with no history of coronary artery disease, ongoing systemic illnesses or steroid treatment, were selected; BMI and serum fasting levels of hs-CRP taken; arbitrarily divided into three groups, having hs-CRP levels (i) $<1 \mathrm{mg} / \mathrm{l}$, (ii) $1-3 \mathrm{mg} / \mathrm{l}$, and (iii) $>3 \mathrm{mg} / \mathrm{l}$, and the Mean BMI in each group calculated.

Results: There was significant association between BMI and hs-CRP in both males $(F=13.53 ; p<0.01)$ and females $(F=15.01 ; p<0.01)$. Correlation between the same parameters indicated that there was positive correlation $(r=0.054 ; p<0.01)$.

Conclusions/Implications: Further, longitudinal studies can done to estimate the role of dietary factors and chronic effect of anti-inflammatory medications on $h$-CRP and BMI respectively.

Keywords:High Sensitivity C-Reactive Protein, Body Mass Index, Atherosclerosis, Coronary Artery Disease

Introduction

C-reactive protein (CRP) is a protein found in blood plasma, whose levels rise in response to inflammation. It is an acute-phase protein of hepatic origin that increases following interleukin- 6 secretion by macrophages and $T$ cells. Its physiological role is to bind to lysophosphatidylcholine expressed on the surface of dead or dying cells (and some types of bacteria) in order to activate the complement system. CReactive Protein or CRP was discovered as the Acute Phase Reactant precipitating C-type polysaccharide in the cell wall of Streptococcus pneumoniae. The high-sensitivity C-Reactive Protein (hs-CRP) has long been known as a marker for low-grade inflammation and atherosclerosis $^{[1]}$. Inflammatory markers have been found in obesity-related syndromes as well $^{[2,3]}$. As Obesity and atherosclerosis-related
\end{abstract}


Coronary Artery Disease goes hand-in-hand, the serum inflammatory marker could evaluate the extent of CAD. Physiological range of CRP $<12$ $\mathrm{mg} / \mathrm{L}$. The reasons for a link between hs-CRP and BMI are not fully understood. One explanation may be that adipose tissue in obese persons releases increased amounts of cytokines into the circulation; this in turn accounts for a greater production of CRP by the liver. ${ }^{[4]}$ The American Heart Association and U.S. Centers for Disease Control and Prevention have defined CAD risk groups based on hs-CRP levels as follows: Low risk: less than $1.0 \mathrm{mg} / \mathrm{L}$; Average risk: 1.0 to 3.0 $\mathrm{mg} / \mathrm{L}$; High risk: above $3.0 \mathrm{mg} / \mathrm{L}$.

Rat studies have shown that hyperuricemiainduced hypertension and vascular disease are partially reversed by the supplementation of the NOS substrate, l-arginine. ${ }^{[5,6]}$ Neogi et $\mathrm{al}^{[7]}$ found that Serum Uric Acid is not associated with coronary artery calcification, a known marker for early preclinical coronary artery disease (CAD) but, on the contrary, Krishnan et al. ${ }^{[8]}$ recently showed that, after adjustment for many confounding factors, elevated SUA levels correlated with the presence and severity of coronary artery calcification in a cohort of young healthy adults.

\section{Objective}

To study the association of hs-CRP with BMI in a population of 25-45 years in Alappuzha, Kerala.

\section{Review of Literature}

In 1973, Keys et al argued that what he termed the BMI was ".. if not fully satisfactory, at least as good as any other relative weight index as an indicator of relative obesity". ${ }^{9]}$ Aronson et al, in his study relating fasting glucose levels and hsCRP levels, showed that glycemic control is positively and significantly associated with elevated hs-CRP in the blood of middle-aged subjects and established a crude positive correlation between hs-CRP and Serum Uric acid levels ( $\mathrm{r}=0.11-0.36) .{ }^{[10]}$ Higher quantities of uric acid were associated with a worse cardiovascular risk profile and a worse kidney function profile in non-hospitalised population. High levels of CRP has been associated to point mutation Cys130Arg in APOE gene, coding for apolipoprotein E, establishing a biochemical link between lipid values and inflammatory markers modulation.

The use of Aspirin(long term low dose), antioxidants like Vitamin C(ascorbic acid) and $\mathrm{N}$-Acetyl Cysteine have shown significant lowering of CRP levels, in subjects with comorbid conditions. ${ }^{[1,12]}$ Reduction of CRP level has also been noted in individuals with known cardiovascular disease who begin aspirin therapy. In those without known cardiovascular disease or significant risk factors for it, aspirin use is not generally recommended. Some diabetic medications, especially, thiazolidinediones have also been shown to reduce CRP levels in people with or without diabetes mellitus, independent of their glucose-lowering affects. ${ }^{[13]}$

\section{Rationale of the Study}

C-Reactive Protein or CRP was discovered as the Acute Phase Reactant precipitating C-type polysaccharide in the cell wall of Streptococcus pneumoniae. The high-sensitivity C-Reactive Protein (hs-CRP) has long been known as a marker for low-grade inflammation and atherosclerosis, and inflammatory markers have been found in obesity-related syndromes as well. As Obesity and atherosclerosis-related Coronary Artery Disease goes hand-in-hand, the serum inflammatory marker could evaluate the extent of CAD. The physiological range of CRP $<12 \mathrm{mg} / \mathrm{L}$. Due to the increasing incidence of Obesityrelated heart disease, a preventive strategy can be adopted in this way. The existence of higher levels of oxidative stress and certain ROS (Reactive Oxygen Species) in inflammatory conditions has been established, contributing to the same. Hence, CRP maybe used as predictive markers and as a prognostic tool in the evaluation of atherosclerotic diseases. However, prediction model studies are required to establish cut-offs of 
CRP values for prognostic implications. Supplementation of exogenous antioxidants like $\mathrm{N}$-acetyl cysteine, EPA (Eicosa Pentanoic Acid) and DHA (Docosa Hexanoic Acid) in patients with documented oxidative stress have shown an improvement in co-morbid conditions, and is a promising new direction of research, in relation to our study as well.

\section{Materials \& Methods}

After obtaining approval from Institutional Research Committee and the Institutional Ethics Committee, 111 apparently healthy subjects of either sex were investigated, over a period of ten months from a tertiary care centre in Alappuzha. Inclusion criteria consisted of subjects of either sex, between 25-45 years, not on any regular medications and not receiving any antibiotics at present. The exclusion criteria consisted of those with a history of coronary artery disease, those with major systemic illnesses, those receiving steroid treatment, febrile subjects, pregnancy, long-standing gout and those with abnormalities of growth and/or development.

\section{Study Procedure}

Sample size $=4 \mathrm{pq} / \mathrm{d}^{2}$

hs- CRP was measured after at least six hours of overnight fasting and quantitative analysis done by Nephelometric method, using Roche Cobas 6000 apparatus. BMI and serum fasting levels of hs-CRP taken; study population was divided into three groups, depending on their CRP levels as group (i) with CRP $<1 \mathrm{mg} / \mathrm{l}$; group (ii) with CRP $=1-3 \mathrm{mg} / \mathrm{l}$; and group (iii) with CRP>3 $\mathrm{mg} / \mathrm{l}$. The Mean BMI in each group was calculated. The significance of variance in BMI, with change in CRP levels was estimated using One-Way ANOVA and computed using SPSS software, version 17.0.

\section{Results}

Fig.1: Percentage distribution of population according to hs-CRP

\section{$\%$ of population(hs-CRP)}

\ $>3 \mathrm{mg} / \mathrm{l} \quad \times 1-3 \mathrm{mg} / \mathrm{l} \quad \mathbb{2}<1 \mathrm{mg} / \mathrm{l}$

From Fig.1, based on the quantified levels of CRP, there were $35.1 \%, 35.1 \%$ and $29.7 \%$ with hs-CRP values <1.0, $1.0-3.0$ and $>3$ respectively. This is based on the risk groups for CAD, as defined by the American Heart Association and U.S. Centers for Disease Control and Prevention as low risk: less than $1.0 \mathrm{mg} / \mathrm{L}$; average risk: 1.0 to $3.0 \mathrm{mg} / \mathrm{L}$ and high risk: above $3.0 \mathrm{mg} / \mathrm{L}$. The mean CRP levels were $1.9 \mathrm{mg} / \mathrm{L}$, $\mathrm{SD}=1.8$.

Table 1. Analysis of variance (ANOVA) between hs-CRP and BMI in Males and Females.

\begin{tabular}{|c|c|c|c|c|c|}
\hline \multirow[b]{2}{*}{ Gender } & \multirow[b]{2}{*}{$\operatorname{CRP}(\mathrm{mg} / \mathrm{L})$} & \multicolumn{2}{|c|}{ BMI (kg/m2) } & \multirow[b]{2}{*}{$\mathbf{F}$} & \multirow[b]{2}{*}{$\begin{array}{c}\mathbf{p} \\
\text { value }\end{array}$} \\
\hline & & Mean & $\operatorname{SD}(\%)$ & & \\
\hline \multirow{3}{*}{ Male } & $<=1$ & 21.9 & 2.5 & \multirow{3}{*}{$13.53 * *$} & \multirow{3}{*}{$<0.01$} \\
\hline & $1.01-3.0$ & 25.8 & 2.3 & & \\
\hline & $>3.0$ & 28.3 & 3.4 & & \\
\hline \multirow{3}{*}{ Female } & $<=1$ & 22.2 & 3.7 & \multirow{3}{*}{$15.01 * *$} & \multirow{3}{*}{$<0.01$} \\
\hline & $1.01-3.0$ & 25.1 & 3.4 & & \\
\hline & $>3.0$ & 28.2 & 3.4 & & \\
\hline
\end{tabular}

Table 1 reveals the comparison of BMI between populations having hs-CRP levels of (i) $<1 \mathrm{mg} / \mathrm{L}$, (ii) $1-3 \mathrm{mg} / \mathrm{L}$ and (iii) $>3 \mathrm{mg} / \mathrm{L}$ revealed significant association between the parameters. (ANOVA, $\mathrm{F}=13.53$ (males); $\mathrm{F}=15.01$ (females), $\mathrm{p}<0.01$ ).

From Fig. 2, the percentage of population having BMI of $<25,25-30$ and $>30$ were 54.1, 37.8 and 8.1 respectively. $<25$ falls under normal BMI 
category, 25 to 30 under overweight and >30 under obesity in Indian population standards.

Fig.2: Percentage distribution of population according to BMI

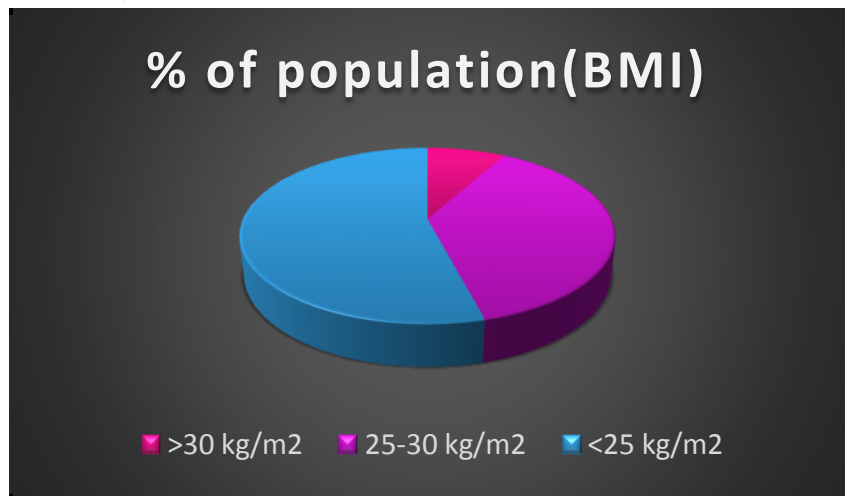

Fig 3 Correlation curve of hs-CRP Vs BMI (below)

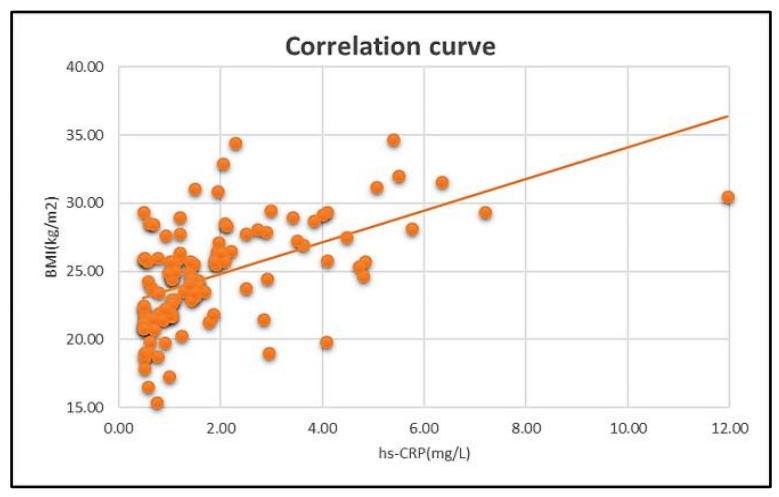

$\mathrm{r}=0.534^{*} *, \mathrm{p}=<0.01$

From Fig.3, correlation of hs-CRP with BMI was found to be highly significant; Pearson correlation coefficient, $r=0.534, \mathrm{p}<0.01$.

Fig. 4 shows correlation of hs-CRP with Uric acid shows positive correlation with Pearson correlation coefficient $r=0.315 ; \mathrm{p}<0.01$, showing high significance.

Fig.4. Correlation curve of hs-CRP Vs Serum Uric Acid. (below))

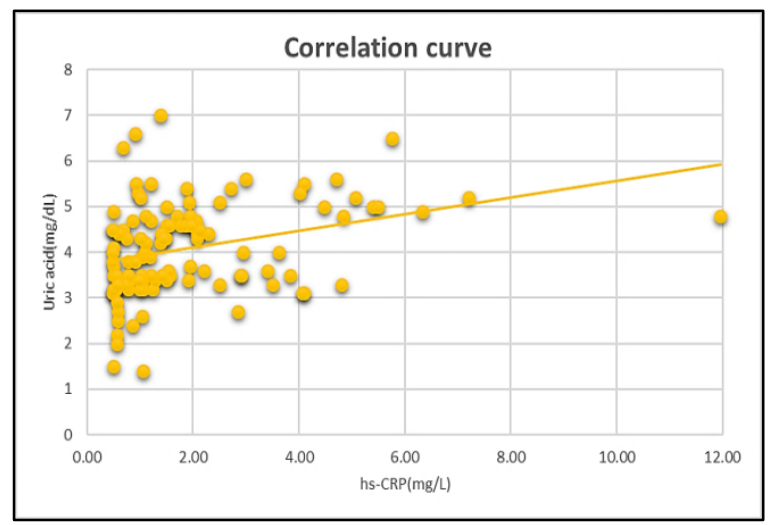

$\mathrm{r}=0.315^{* *} ; \mathrm{p}<0.01$
Fig.5: Correlation curve of SUA Vs BMI(below)

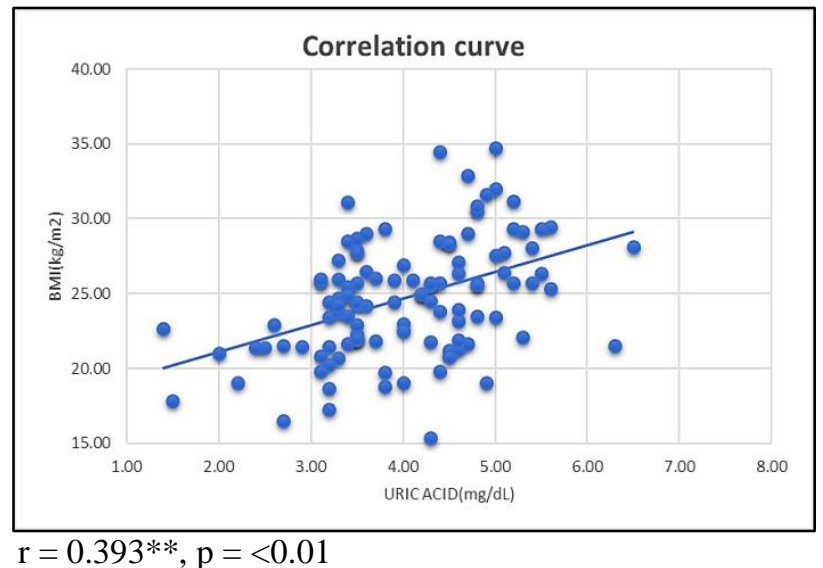

Fig.5 shows correlation of Uric acid with BMI shows positive correlation, with Pearson correlation coefficient $\mathrm{r}=0.393$, significant at 0.01 level.

\section{Conclusion}

In this study, there is significant correlation between hs-CRP and BMI (Pearson correlation, $\mathrm{r}=0.534, \mathrm{p}<0.01$ ), Serum Uric acid levels and BMI (Pearson correlation, $r=0.393, \mathrm{p}<0.01$ ), and also between hs-CRP and Serum Uric Acid levels (Pearson correlation, $\mathrm{r}=0.315, \mathrm{p}<0.01$ ), in the local population of Alappuzha, Kerala. The existence of higher levels of oxidative stress and certain ROS (Reactive Oxygen Species) in inflammatory conditions has been established, contributing to the same. Supplementation of exogenous antioxidants like $\mathrm{N}$-acetyl cysteine, EPA (Eicosa Pentanoic Acid) and DHA (Docosa Hexanoic Acid) in patients with documented oxidative stress have shown an improvement in co-morbid conditions. ${ }^{[13]}$

CRP maybe used as predictive markers and as a prognostic tool in the evaluation of atherosclerotic diseases. Assessment of association between the variables hs-CRP and BMI showed significant results (ANOVA, $\mathrm{F}=13.53$ (males), $\mathrm{p}<0.01 ; \quad \mathrm{F}=15.01$ (females), $\quad \mathrm{p}<0.01$ ). This statistical analysis showed that males with moderate (hs-CRP=1-3 mg/L) and high (hsCRP>3 mg/L) risk for developing CAD had average BMI values of $25.8 \pm 2.3 \mathrm{~kg} / \mathrm{m}^{2}$ and $28.3 \pm 3.4 \mathrm{~kg} / \mathrm{m}^{2}$ respectively, and similar groups among female population had BMI of $25.1 \pm 3.4$ 
$\mathrm{kg} / \mathrm{m}^{2}$ and $28.2 \pm 3.4 \mathrm{~kg} / \mathrm{m}^{2}$ respectively. The risk groups had overlapping values for BMI, indicating that there is no clear cut-off range for predicting the degree of risk associated with elevated BMI, possibly influenced y confounding factors like diet, physical activity, differences in the level of stress hormones, age etc.. CRP could be assessed in children as well as geriatric population for better understanding.

\section{Acknowledgements}

I wish to express my sincere gratitude to Dr. Rose Davy C., Additional Professor, Department of Physiology, Government T.D. Medical College, Alappuzha, without whose guidance, constant support and non-wavering enthusiasm, this study would not have been complete.

I am humbled to receive immense advice, opinions information regarding the topic from $D r$. Deepa Rajendran, Assistant Professor, Government T.D. Medical College, Alappuzha, who guided me whenever help was called for.

I am extremely grateful to Dr. N.Geetha, Professor and Head, Department of Physiology, Government T.D.Medical College, Alappuzha, for her timely advice.

I am forever thankful to Dr. Vijayalekshmi M.T., currently Professor and Head, Department of Physiology, Government Medical College, Thrissur

\section{References}

1. Yang SP, Gong CX, Cao BY, Yan C. Relationship between serum highsensitivity C-reactive protein and obesity and impaired glycose metabolism in children and adolescents. Zhonghua $\mathrm{Er} \mathrm{Ke}$ Za Zhi. 2006;44(12):933-936.

2. Barbosa MC, Brandão AA, Pozzan R, Magalhães ME, Campana EM, Fonseca FL, Pizzi OL, Freitas EV, Brandão AP.Association between uric acid and cardiovascular risk variables in a non-hospitalized population. Arq Bras Cardiol. 2011 Mar;96(3):212-8.
3. Abdullah AR, Hasan HA, Raigangar VL.Analysis of the relationship of leptin, high-sensitivity C-reactive protein, adiponectin, insulin, and uric acid to metabolic syndrome in lean, overweight, and obese young females. Metab Syndr Relat Disord. 2009 Feb;7(1):17-22.

4. Go AS, Chertow GM, Fan D, McCulloch $\mathrm{CE}, \mathrm{Hsu} \mathrm{CY}$. "Chronic kidney disease and the risks of death, cardiovascular events, and hospitalization". N. Engl. J. Med. September 2004;351(13):1296-1305.

5. Graham L., Atar D., Borch-Johnsen K., Boysen G., Burell G., Cifkova R., et al. European guidelines on cardiovascular disease prevention in clinical practice: executive summary: Fourth Joint Task Force of the European Society of Cardiology and Other Societies on Cardiovascular Disease Prevention in Clinical Practice. Circulation. 2004;109:2818-2825.

6. Oda E., Kawai R. Tentative cut point of high-sensitivity C-reactive protein for a component of metabolic syndrome in Japanese. Circ. J. 2009;73:755-759.

7. Neogi, T., Terkeltaub, R., Ellison, R.C., Hunt, S., and Zhang, Y. Serum urate is not associated with coronary artery calcification: the NHLBI Family Heart Study. J Rheumatol. 2011; 38: 111-117

8. Krishnan, E., Pandya, B.J., Chung, L., and Dabbous O. Hyperuricemia and the risk for subclinical coronary atherosclerosisdata from a prospective observational cohort study. Arthritis Res Ther.2011; 13: R66

9. Keys, Ancel; Fidanza, Flaminio; Karvonen, Martti J.; Kimura, Noboru; Taylor, Henry L. "Indices of relative weight and obesity". Journal of Chronic Diseases.1972;25 (6-7): 329-43.

10. D. Aronson, P. Bartha, O. Zinder, A. Kerner, E. Shitman, W. Markiewicz et al. Association between fasting glucose and 
C-reactive protein in middle-aged subjects. Diabetic Medicine- Online Open; 2004 Jan; 21(1); 39-44.

11. Grunwald T., Fadia S. Bernstein B. et al. Vitamin D supplementation, the Metabolic Syndrome and Oxidative Stress in Obese Children.; J Pediatr Endocrine Metab.; 2017 Apr 1;30(4):383-388.

12. Kawai VK, Avalos I, C. Michael Stein, et al. Suboptimal inhibition of platelet cyclooxygenase-1(COX-1) by aspirin in lupus erythematosus: Association with metabolic syndrome. Arthritis Care Res (Hoboken). 2014 Feb;66(2):285-92.

13. Mohan IK, Das UN. Oxidant Stress, antioxidants and essential fatty acids in systemic lupus erythematosus. Prostaglandins Leukot Essent Fatty Acids. 1997 Mar;56(3):193-8. 